\title{
Capping of a surface slurried coal tailings storage facility
}

\author{
DJ Williams The University of Queensland, Australia \\ G King New Acland Operations, Australia
}

\begin{abstract}
A completed, conventional, surface slurried coal tailings storage facility in Southeast Queensland, Australia, required capping to facilitate rehabilitation for grazing purposes. The facility had been closed for some years and the upper part of the tailings beach was well-desiccated, while residual ponds covered the low areas with the extent of ponding varying with rainfall. Prior to the commencement of capping, the tailings were tested using a field shear vane, the results of which were used to assess the safe trafficking of the dozer and placement of the initial capping layer. Both the peak and remoulded vane shear strengths were tested, the former representing small-strain loading and the latter representing bow-waving. An initial 1 to $2 \mathrm{~m}$ deep capping layer of coarse reject was placed using a D6 Swamp Dozer. Capping commenced from the strongest, highest elevation of the tailings beach, and extended towards the ponds. As the capping progressed, further vane shear testing was carried out to assess the shear strength of the tailings beyond the capping layer, and the strength gain over time in the already covered tailings, which would enable further capping material to be safely placed. The paper describes the capping approach and sequence adopted. The initial capping was followed by the placement of further coarse reject by D9 Dozer.
\end{abstract}

\section{Introduction}

New Hope Group's New Acland Coal Mine in the Clarence Moreton Basin within the lower Walloon Coal Measures, is located north-west of Oakey in Southeast Queensland, Australia (New Hope Group 2015). Initially, New Acland discharged slurried tailings generated by their coal processing plant to a surface tailings storage facility (TSF1 and TSF1 Extension), before establishing in-pit TSFs (Figure 1).

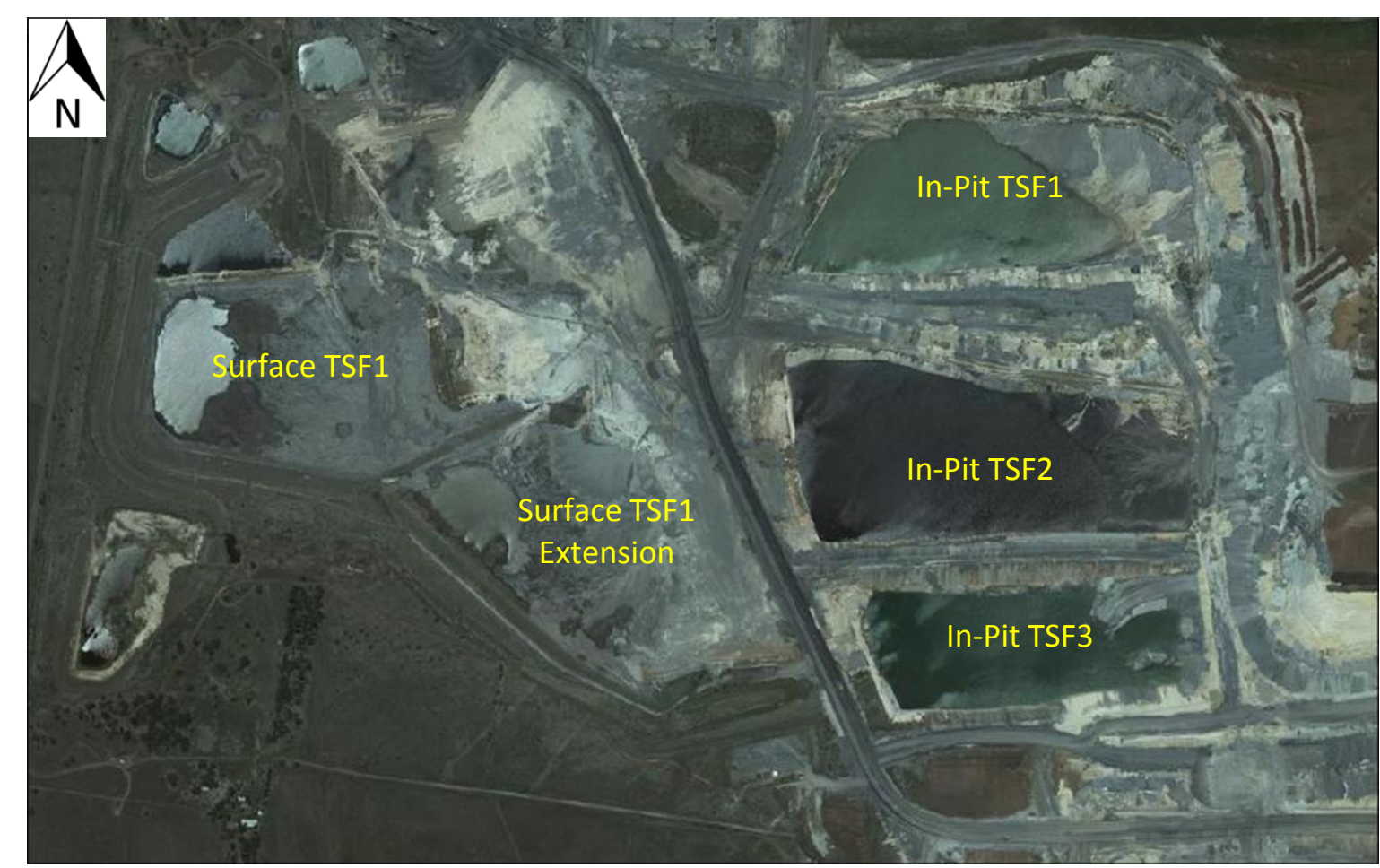

Figure 1 New Acland surface and in-pit TSFs (aerial photograph taken on 12 March 2013) 
Sometime after the cessation of tailings deposition, following surface crusting, spoil was dumped from haul trucks into the surface TSF from the northern and eastern upper tailings beach. However, this resulted in bow-waving of the crusted tailings. Spoil placement was stopped when a 1 to $1.5 \mathrm{~m}$ high bow-wave overtopped the bund dividing TSF1 from TSF1 Extension, and approached the southern external wall of TSF1. Subsequently, New Acland committed to more effectively capping the surface TSF.

\section{$2 \quad$ Capping surface TSF}

The capping of the New Acland surface TSF required the selection of the capping method and best-suited capping materials, assessment of the shear strength and bearing capacity of crusted coal tailings, and the vane shear strength testing of the crusted tailings in the New Acland surface TSF ahead of capping. This was backed-up by associated laboratory testing of representative TSF tailings samples, and observations of the initial capping of the surface TSF.

\subsection{Selection of capping method and material}

The bow-waving that occurred on the placement of spoil on the upper northern tailings beach of the New Acland surface TSF highlighted the need to select a less impacting capping method. Coarse reject from the coal preparation plant was proposed as the initial capping material due to its availability as a waste material that had to be disposed of, and it being better-draining than spoil, which degrades rapidly. The overall cover was to comprise an initial thin capping layer of coarse reject, followed by a second thicker layer of coarse reject, and finally a topsoil layer that was to be seeded and fertilised.

Possible capping methods considered included:

- Placement of coarse reject hydraulically which was dismissed due to the infrastructure required.

- Placement of coarse reject by a Rockslinger (Figure 2(a)), which was trialled and found to have insufficient reach. Also, the Rockslinger would have to operate from the southern embankment crest of the TSF which was considered too narrow for safe operation.

- Pushing coarse reject by D6 Swamp Dozer which was adopted (Figure 2(b)).

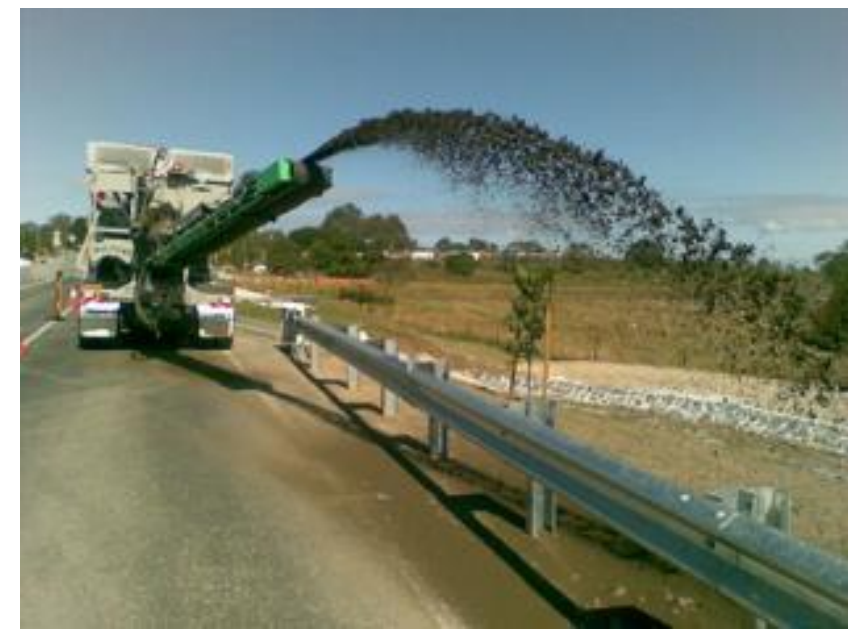

(a)

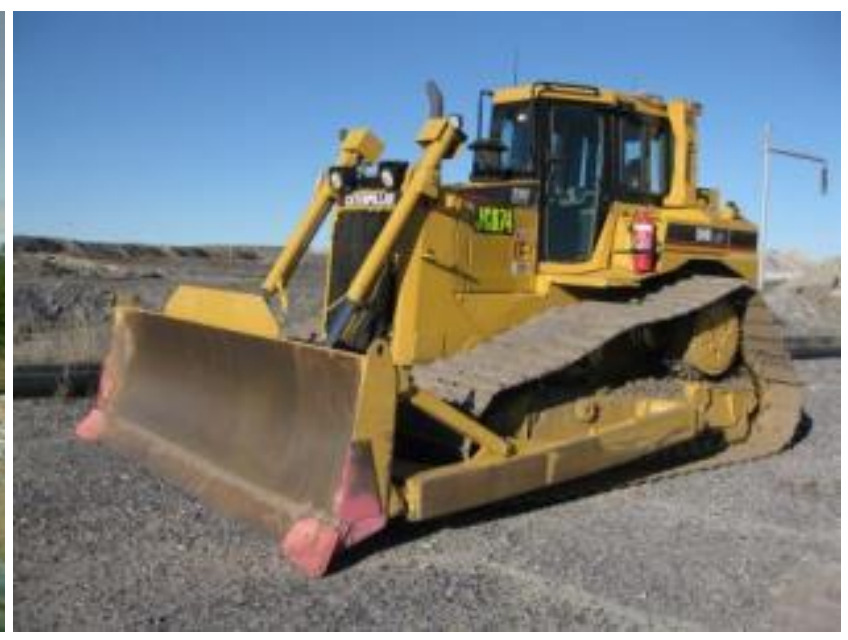

(b)

Figure 2 Alternative capping methods: (a) Rockslinger, and (b) D6 Swamp Dozer

The D6 Swamp Dozer (Model CAT D6R III LGP, with an operating mass of $21.7 \mathrm{t}$ ) exerts an average track bearing pressure of $35 \mathrm{kPa}$, equivalent in bearing pressure to about $1 \mathrm{~m}$ height of fill. This needs to be taken into account in addition to the height of fill placed, to ensure safe operation on the crusted tailings. 


\subsection{Assessing shear strength and bearing capacity of coal tailings}

Given the difficulty of sampling and generally low shear strength of fine-grained coal tailings, in situ vane shear testing is the most appropriate means of obtaining an estimate of the shear strength profile of the tailings with depth. Both the peak and remoulded vane shear strengths should be measured. The peak vane shear strength is the value obtained on initial shearing, while the remoulded vane shear strength is the value obtained on re-shearing after remoulding by rotating the vane a nominal three revolutions. The vane shear strength of the tailings $s_{v}$ is estimated using:

$$
s_{v}=T 10^{6} /\left[\pi\left(D^{2} H / 2+D^{3} / 6\right)\right]
$$

where:

$$
\begin{aligned}
T= & \text { measured (peak or remoulded) torque in N.m. } \\
D= & \text { vane shear diameter. } \\
H \quad= & \text { vane shear height (typically twice the diameter, to limit the shear resistance on the ends of } \\
& \text { the vane to about } 10 \% \text { of the total shear resistance on the vane). }
\end{aligned}
$$

Equation (1) assumes that the vane scribes a cylinder, with uniform stresses generated on its vertical sides, reducing to zero at the axis of rotation of the vane. Figure 3 shows a number of shear strength profiles with depth measured by the first author in crusted coal tailings at Ulan Coal Mine in New South Wales. The underwater profile represents consolidation of the coal tailings due to their self-weight alone (based on their low specific gravity of about 1.8), assuming that the tailings always remain underwater. Self-weight consolidation of the coal tailings results in a liner increase in shear strength of about $0.8 \mathrm{kPa} / \mathrm{m}$ depth.

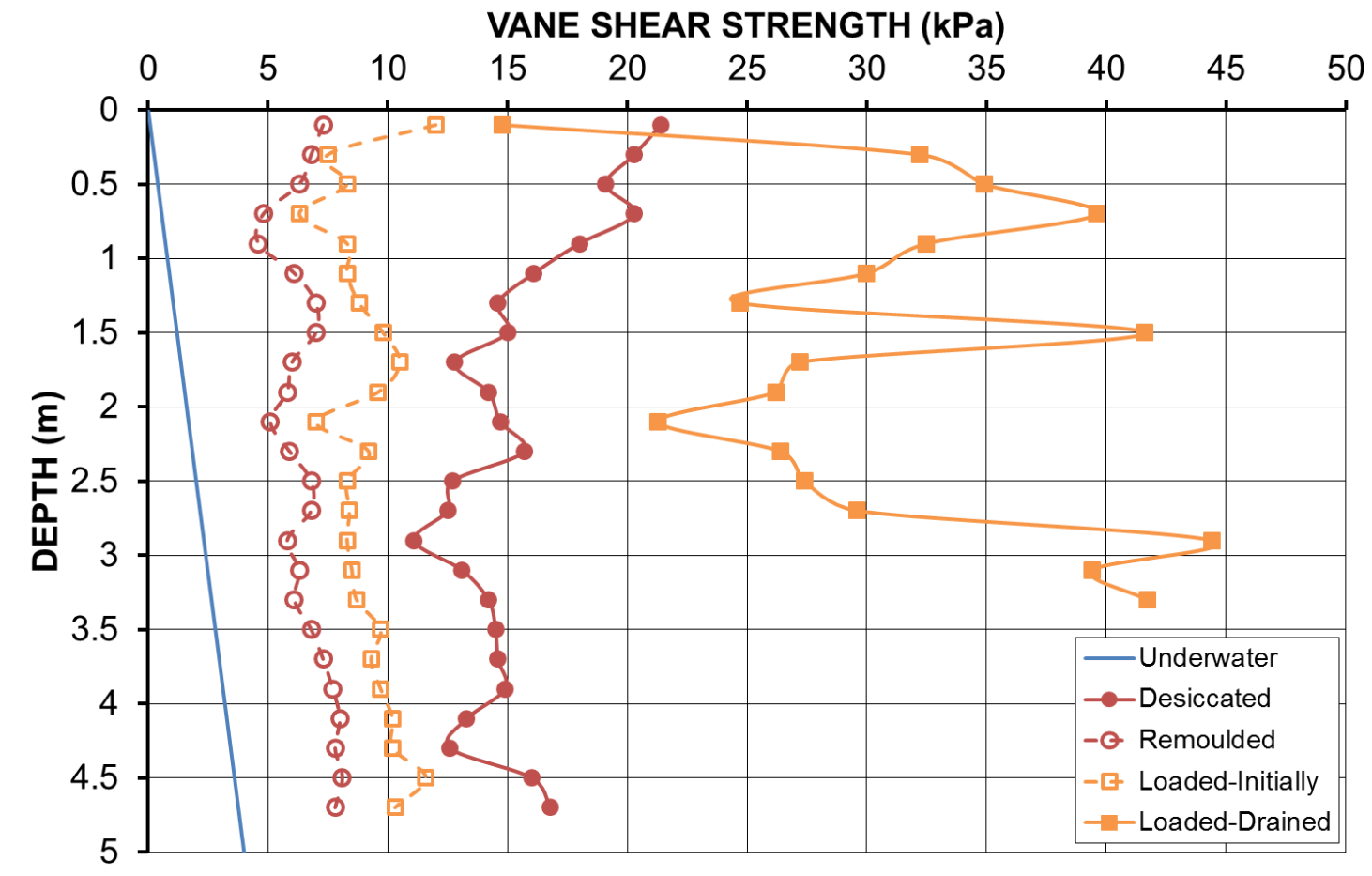

Figure 3 Vane shear strength profiles with depth for Ulan coal tailings

The measured desiccated profile represents the peak vane shear strengths obtained on initial shearing using the vane, and shows a number of remnant crusts on intermediate layers of tailings that were exposed and underwent desiccation. Note that desiccation due to solar and wind drying drops off exponentially with depth and has little effect below about $1 \mathrm{~m}$ depth. The subsequent deposition of fresh tailings on these desiccated crusts caused some reversal in their shear strength. Overall, the desiccated profile has a peak vane shear strength averaging about $15 \mathrm{kPa}$. The measured remoulded profile represents corresponding remoulded vane shear strengths obtained after several revolutions of the vane, which average less than 
half the peak values. The remoulded profile corresponds to the shear strength available should a bow-wave be initiated due to rapid overloading of the crusted tailings.

The loaded-initially profile was measured within 12 hours of a 4 to $5 \mathrm{~m}$ high layer of spoil being placed on the desiccated tailings (Figure 4), which caused remoulding of the tailings accompanied by the formation of a bow-wave, and a drop in vane shear strength towards the previous remoulded profile. The loaded-drained profile was measured about one week after spoil placement, and shows a dramatic increase in the peak vane shear strength to an average about $30 \mathrm{kPa}$, twice the desiccated profile and over four times the remoulded profile. In the loaded-drained profile, the drop in shear strength towards the surface is due to the desiccated near-surface tailings having a much-reduced (unsaturated) hydraulic conductivity than the near-saturated and less consolidated tailings at depth. Hence, the near-surface tailings are incapable of draining the excess pore water pressures from the more permeable tailings at depth, and they wet-up and soften somewhat (Figure 3).

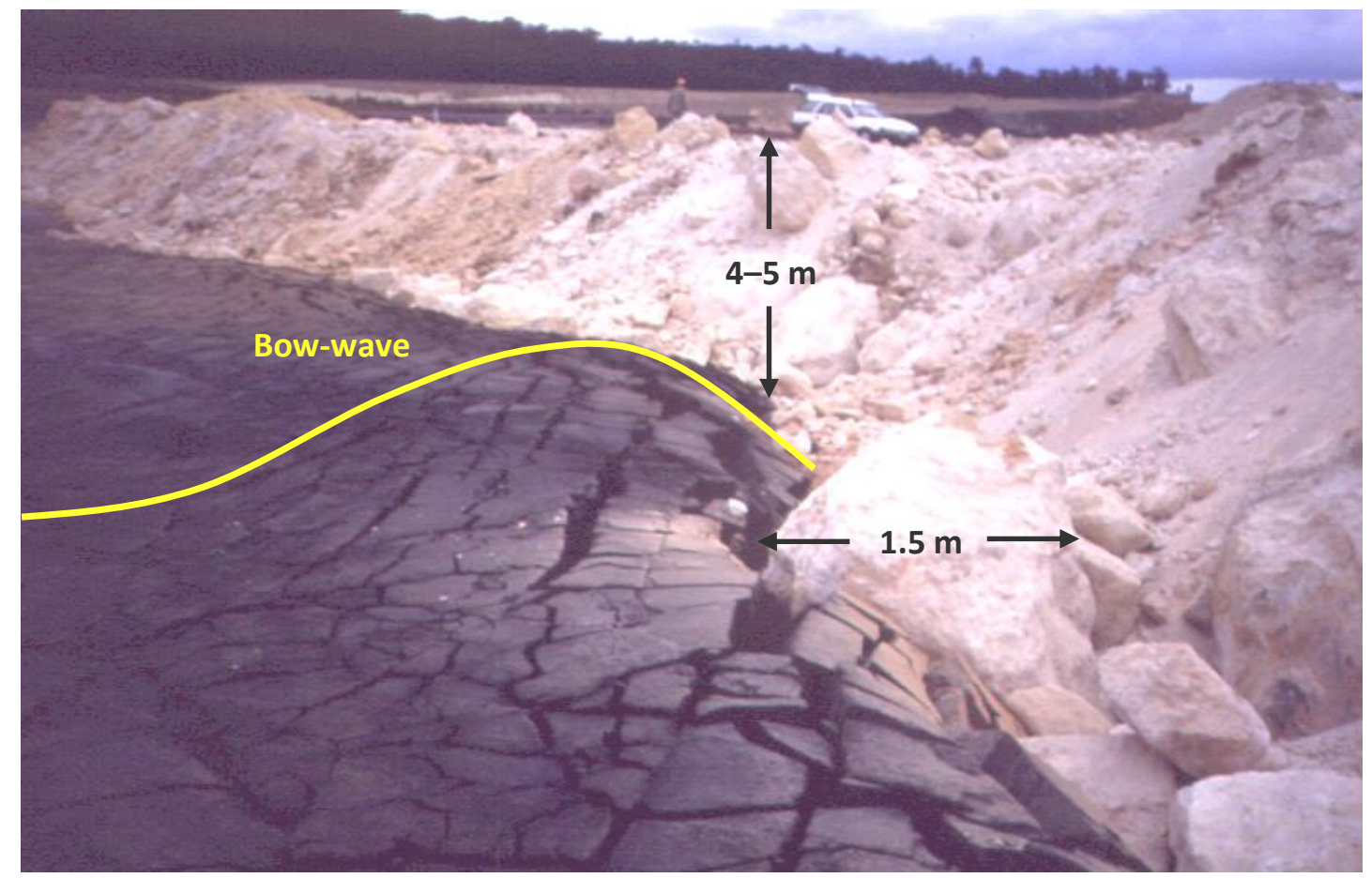

Figure 4 Bow-waving on filling over desiccated coal tailings at Ulan Coal Mine

The fill height $H$ that may safely be placed by pushing using a D6 Swamp Dozer over crusted tailings, without causing remoulding and bow-waving, is given by (adapted from Williams 2005):

$$
H=\left(N_{c} s_{v} / F \gamma\right)-H_{e} \approx\left(5.14 s_{v} /[1.5 \times 18]\right)-1 \approx 0.190 s_{v}-1
$$

where:

$$
\begin{aligned}
N_{c}= & \text { bearing capacity factor }=5.14, \text { assuming that a strip of fill is pushed over a broad front. } \\
F= & \text { adopted factor of safety; a minimum of say } 1.5 . \\
\gamma= & \text { unit weight of the fill, say } 18 \mathrm{kN} / \mathrm{m}^{3} . \\
H_{e}= & \text { equivalent height of fill corresponding to the average bearing capacity of the D6 Swamp } \\
& \text { Dozer } \approx 1 \mathrm{~m} .
\end{aligned}
$$

Note that if the depth and shear strength of the surface crust are limited, and/or there has been no desiccation of previously deposited tailings layers, there will be increased risk of a failure through the crust into the underlying soft tailings, resulting in remoulding and loss of shear strength, followed rapidly by the generation of a bow-wave. If the D6 Swamp Dozer operator feels the initiation of a bow-wave, the dozer 
should immediately be turned off to stop engine vibrations, and the dozer operator should get off the machine. The excess pore water pressures generated by fill placement will dissipate relatively rapidly (over one to four weeks, depending on the hydraulic conductivity of the tailings, affected by their particle size distribution and clay mineral content), after which the dozer should be safe to move and fill placement can recommence.

The peak shear strength of loaded coal tailings will increase as they drain, according to (Williams 2005):

$$
\Delta \tau=\Delta \sigma^{\prime} \tan \phi^{\prime}
$$

where:

$$
\begin{aligned}
\Delta \tau= & \text { increase in the peak shear strength. } \\
\phi^{\prime}= & \text { effective (drained) friction angle of the tailings }\left(\approx 30^{\circ}\right) . \\
\Delta \sigma^{\prime}= & \text { increase in the effective stress following loading by a height of fill } H \text { and drainage of the } \\
& \text { excess pore water pressures generated. }
\end{aligned}
$$

Hence:

$$
\Delta \sigma^{\prime}=\gamma H \approx 18 H
$$

and:

$$
\Delta \tau<18 \mathrm{H} \tan 30^{\circ} \approx 10 \mathrm{H}
$$

on full drainage (after about one to four weeks, depending on the hydraulic conductivity of the tailings).

Note that the peak vane shear strength is a measure of how much additional fill can be placed, since any fill previously placed and left for a sufficient time to dissipate all excess pore water pressures, is already supported.

\subsection{Vane shear strength testing of crusted tailings ahead of capping}

Ahead of the capping of the New Acland surface TSF, the peak and remoulded vane shear strengths, and hence bearing capacities, of the tailings were assessed. The vane shear testing was carried out using The University of Queensland (UQ) hand-operated, $65 \mathrm{~mm}$ diameter by $130 \mathrm{~mm}$ high vane shear and torque wrench (Figure 5). The peak vane shear strength represents that on initial loading, while the remoulded vane shear strength, obtained after three full revolutions of the vane, represents that on bow-waving. The vane shear testing was carried out at depth intervals of $0.2 \mathrm{~m}$, starting at $0.1 \mathrm{~m}$ depth and extending to between 0.9 and $1.9 \mathrm{~m}$ depth. The test hole was advanced by hand augering between vane tests, which also enabled tailings samples to be collected for subsequent laboratory testing at $\cup Q$ (not reported herein).

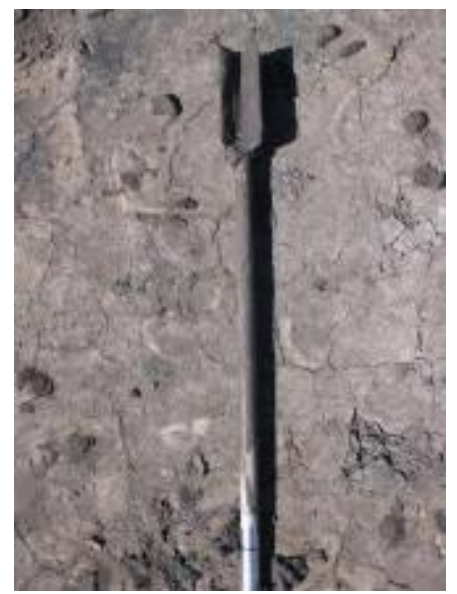

(a)

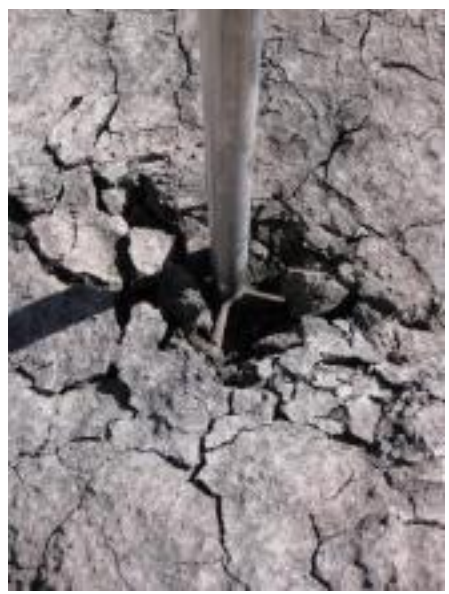

(b)

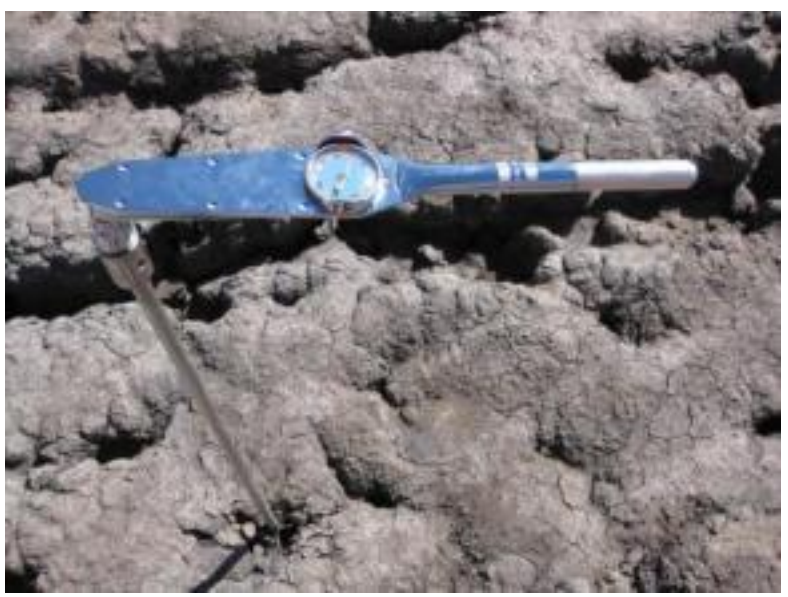

(c)

Figure 5 Vane shear showing: (a) vane shear, (b) vane inserted into tailings, and (c) torque wrench 
The locations of the initial vane shear tests carried out in early May 2012 are shown in Figure 6, with the locations of all vane shear tests carried out in three stages from May to October 2012 shown in Figure 7, which are mainly confined to the more accessible parts of TSF1 Extension. Figure 6 shows the raised crest of the old bow-wave, which was induced by the previous capping using spoil dumped from haul trucks, the nearby southern reeds, and the northern reeds and pond. The peak and remoulded vane shear strength profiles with depth corresponding to the locations shown in Figure 6 are presented in Figure 8.

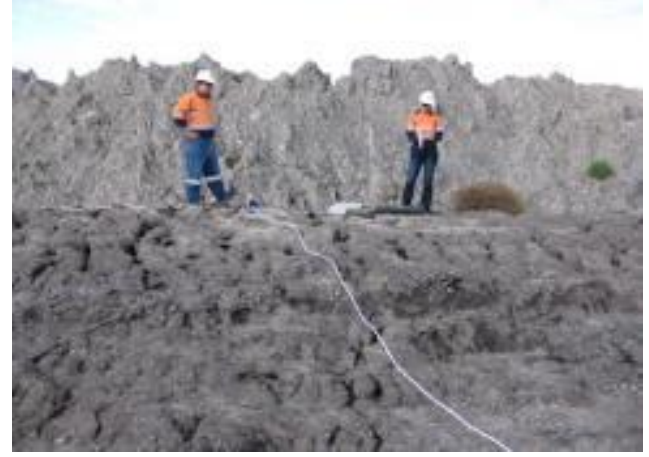

(a)

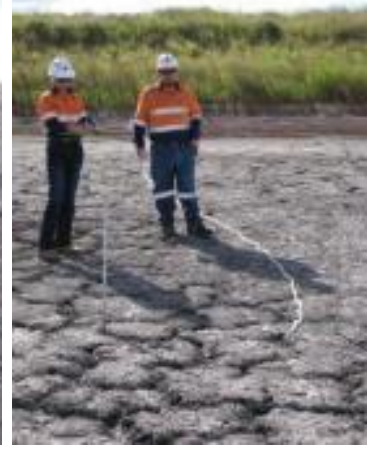

(b)

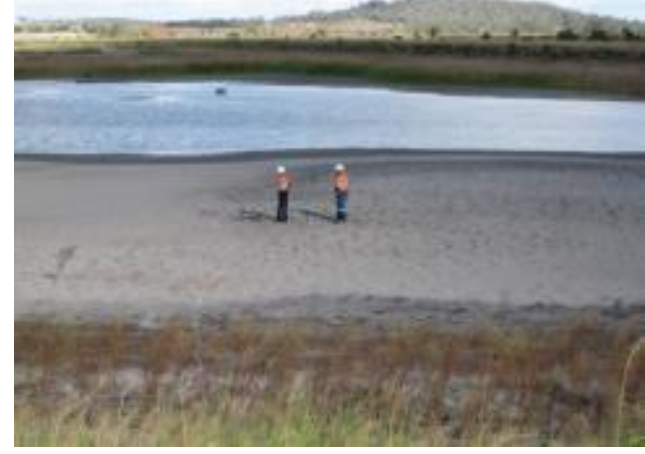

(c)

Figure 6 Vane shear testing at: (a) crest of old bow-wave, (b) southern reeds, and (c) northern reeds

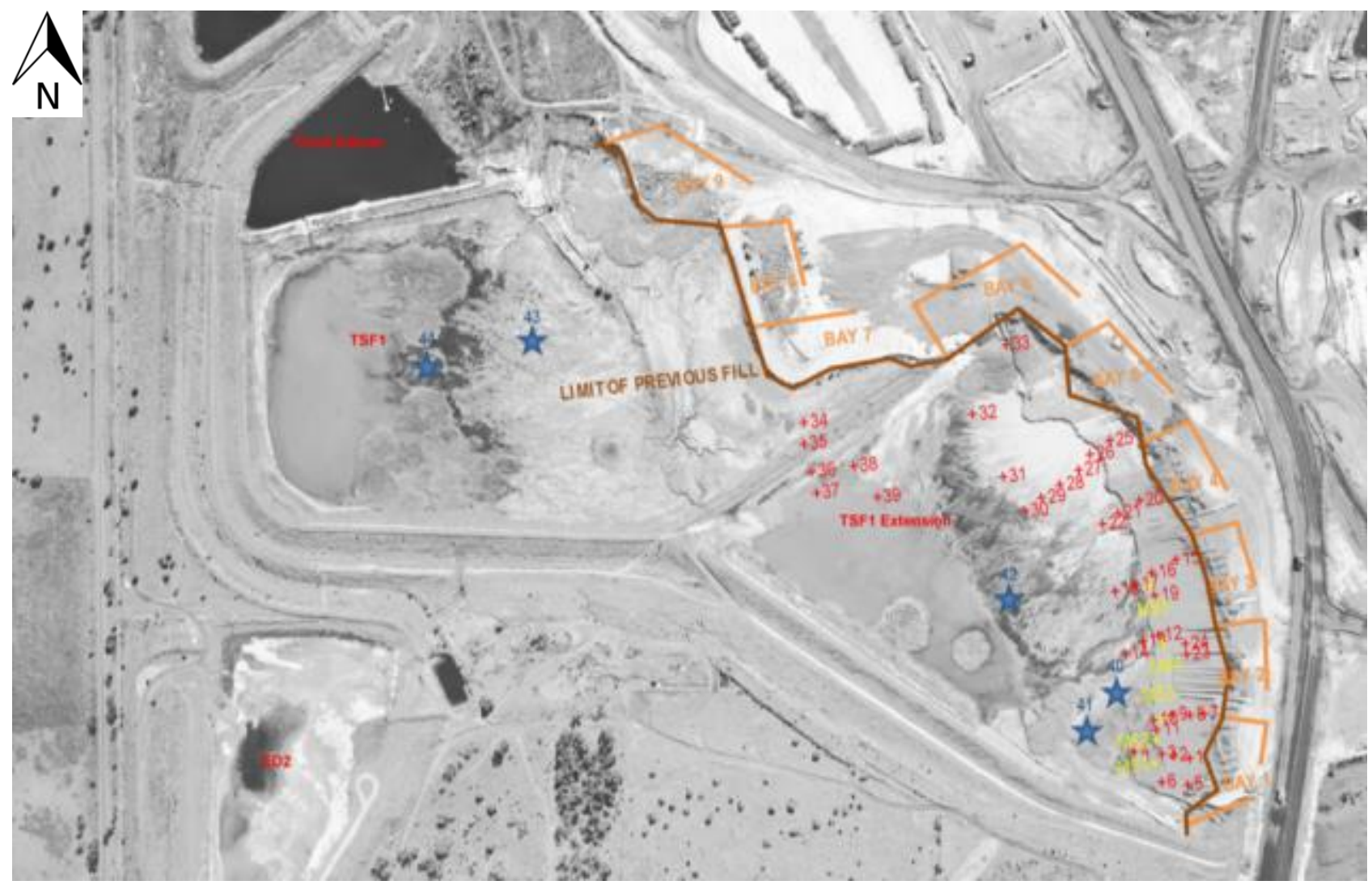

Figure 7 Vane shear test locations in three stages from May to October $2012\left(++\frac{\hbar}{\hbar}\right)$ 


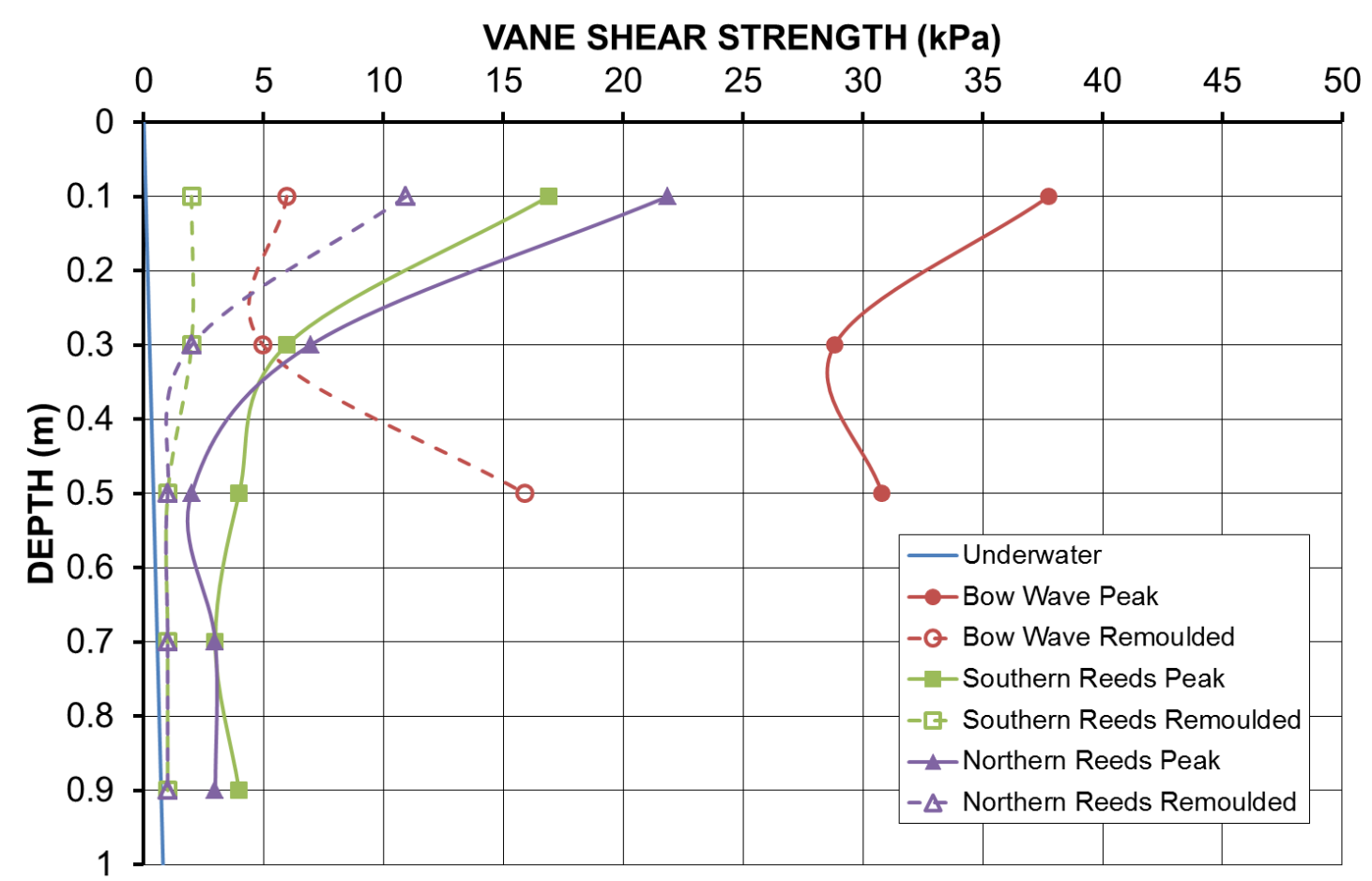

Figure 8 Selected peak and remoulded vane shear strength profiles with depth

The effects of increasing desiccation from the underwater (never-desiccated) state on the peak vane shear strength profiles are presented in Figure 9. The safe fill heights corresponding to the peak vane shear strength profiles in Figure 9, estimated using Equation (2), are presented in Figure 10. Note that the underwater case cannot support the D6 Swamp Dozer or any fill, and is not included. Clearly, the well and deeply-desiccated old bow-wave areas would readily support fill placed by a D6 Swamp Dozer, while the thin surface crust at the northern and southern reeds would struggle to support the D6 Swamp Dozer and any fill it pushes, and surcharging from the edge of this area would be required to drain and increase the shear strength of the tailings at depth.

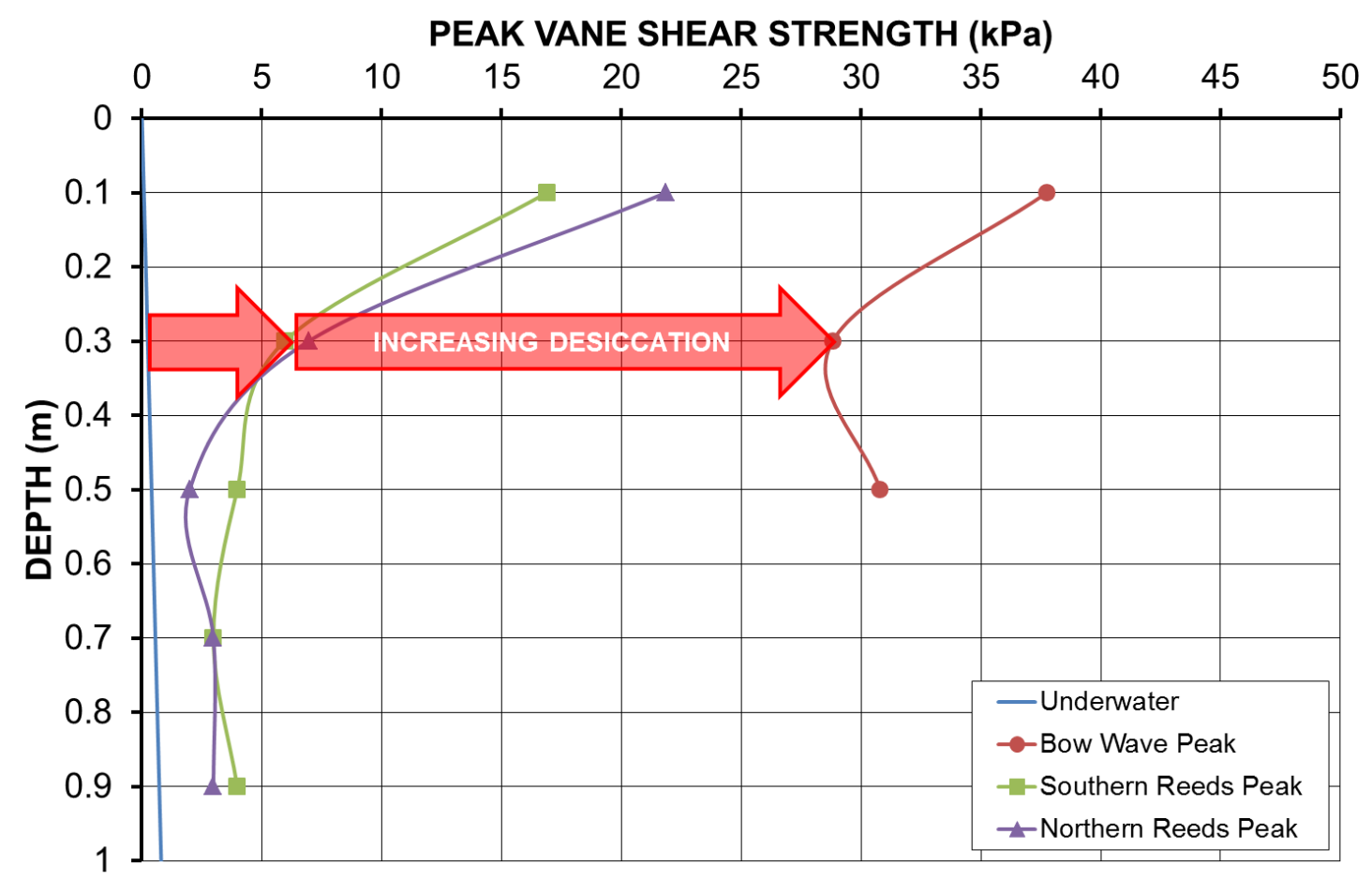

Figure 9 Effects on peak vane shear strength of increasing desiccation 


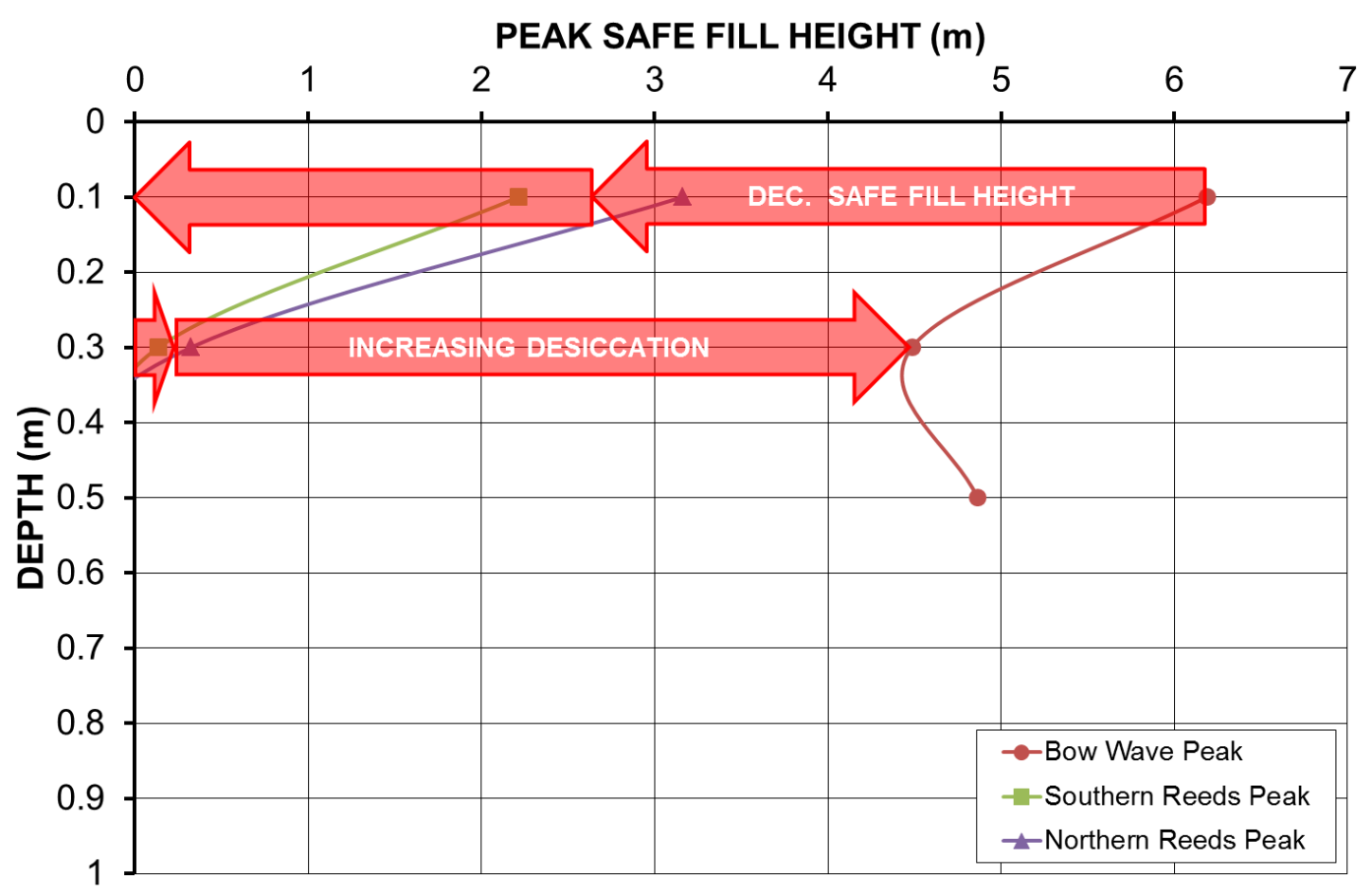

Figure 10 Safe fill height corresponding to peak vane shear strength profiles

Typical ratios of the remoulded to the peak vane shear strength of tailings with depth are shown in Figure 11 , indicating an average ratio of about 0.4 , translating to a $60 \%$ reduction in tailings shear strength, and hence bearing capacity, should remoulding and bow-waving be induced.

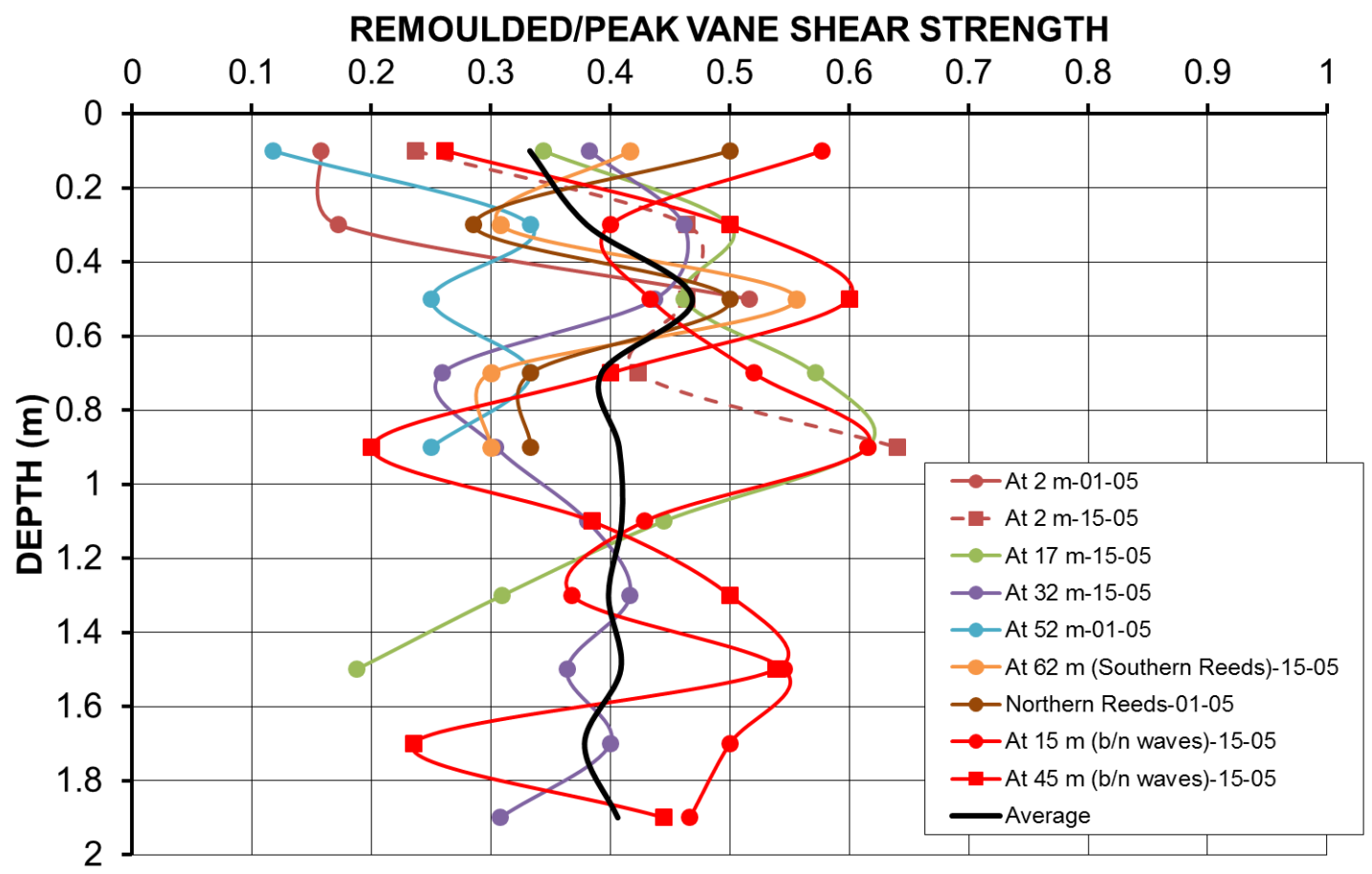

Figure 11 Typical ratios of remoulded to peak vane shear strength of tailings with depth

In addition to the safety concerns associated with uncontrolled bow-waving, bow-waves also push soft tailings to the surface. This makes the completion of the capping more difficult, elevates the final level of the capped surface, and may increase seepage from the soft tailings directly to the environment. It also increases the amount of fill required to complete the initial capping layer, adding to capping costs. 
On the placement of the initial capping layer (typically about $1 \mathrm{~m}$ deep in an effort to avoid bow wave failure), excess pore water pressures are induced in the tailings, raising the water table (often to the surface). These excess pore water pressures dissipate through drainage to the surface, resulting in a general increase and greater uniformity of the peak vane shear strength profile with depth (Figure 12). The increased peak shear strength, averaging $15.3 \mathrm{kPa}$ in Figure 12, would allow an additional fill height of almost $2 \mathrm{~m}$ to be safely placed using the D6 Swamp Dozer.

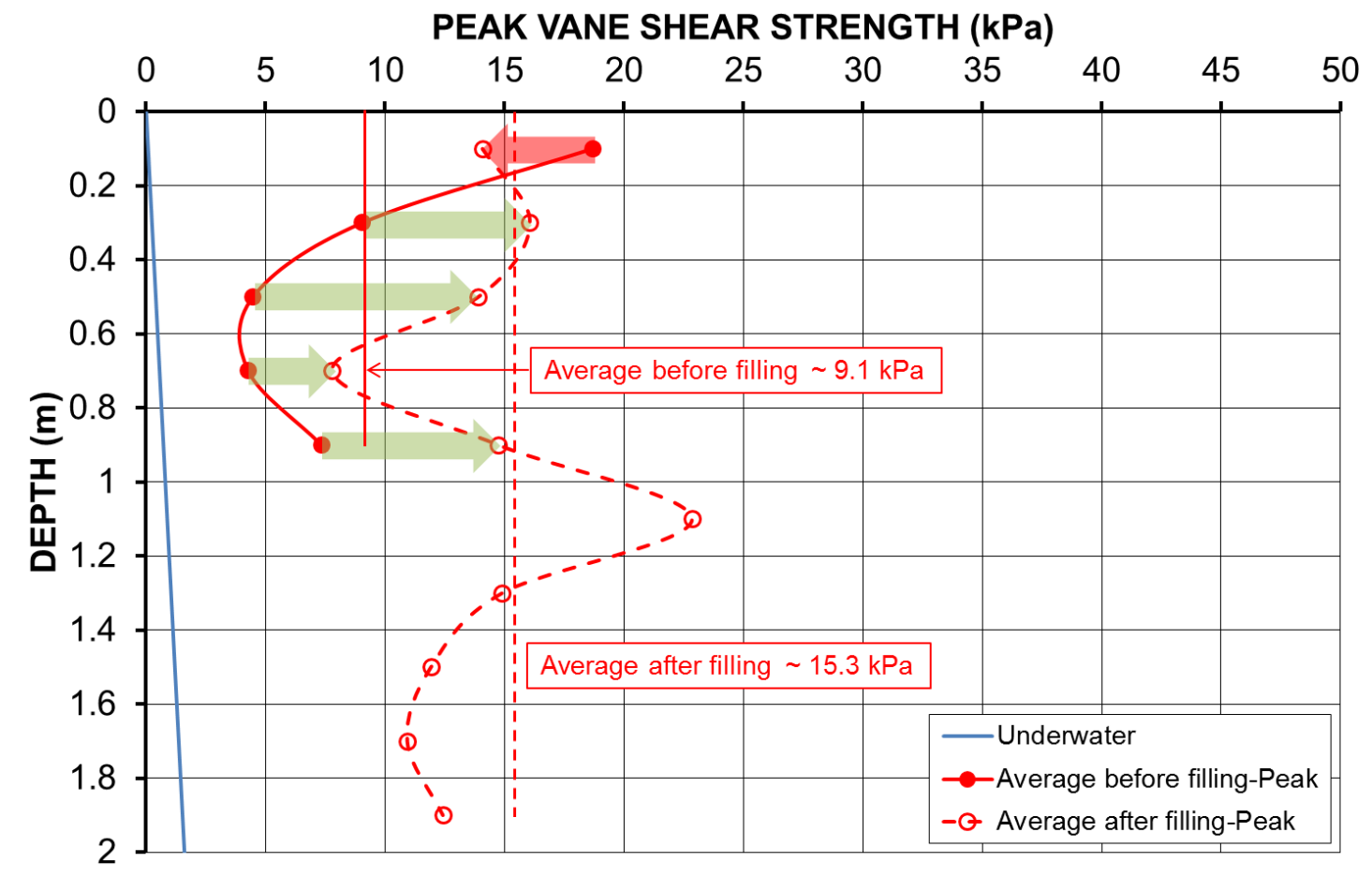

Figure 12 Increase in peak vane shear strength due to dissipation of excess pore water pressures

Note that the successful placement of the initial capping layer over a large area of the tailings surface leads, on the drainage of the excess pore water pressures generated, to an increase in the shear strength of the tailings to full depth, eventually by $10 \mathrm{H} \mathrm{kPa}$ (from Equation (5)). Once the initial capping layer has been placed over the entire surface area of the tailings, any potential for bow-waving on the placement of additional fill is restricted by this initial capping layer. This, and the induced increase in the shear strength of the tailings, makes the placement of additional fill relatively straight-forward, allowing a D9 Dozer to be employed to place a second thicker layer of coarse reject at a far faster rate, at lower cost.

\subsection{Capping experience at New Acland and recommendations}

Photographs of the early pushing of the initial capping of coarse reject over the raised crest of the old bow-wave of the surface TSF at New Acland are shown in Figure 13.
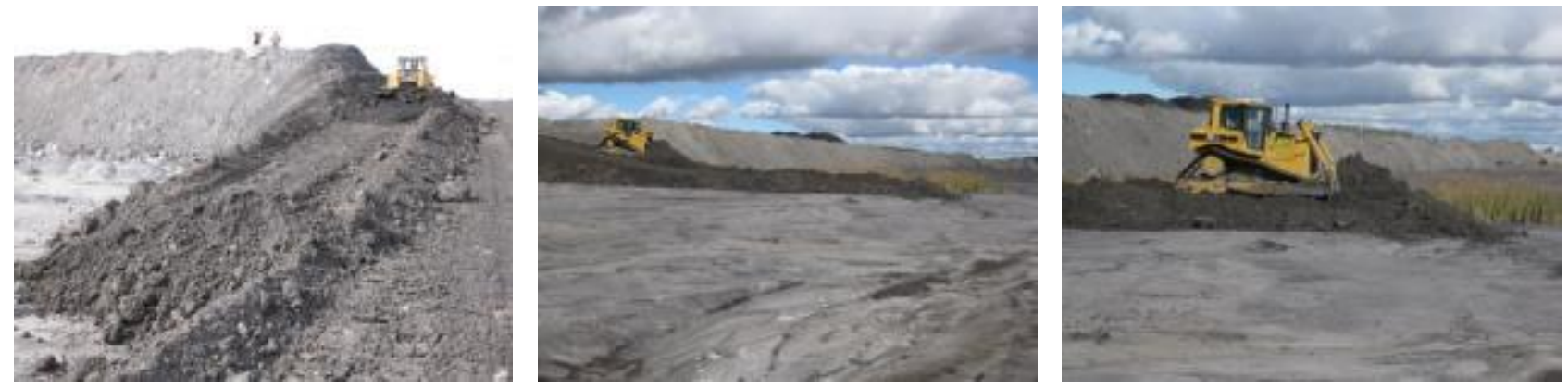

Figure 13 Early pushing of a capping of coarse reject over old bow-wave of surface TSF 
Fill placement caused the tailings to drain, often raising the water table to the surface of the tailings as seen in Figure 14(a). The first sign of imminent bow-waving was the appearance of hydraulic fractures radiating out from the toe of the fill, as seen in Figure 15(b), with continued dozing leading to the formation of a bow-wave (Figure 14(c)).

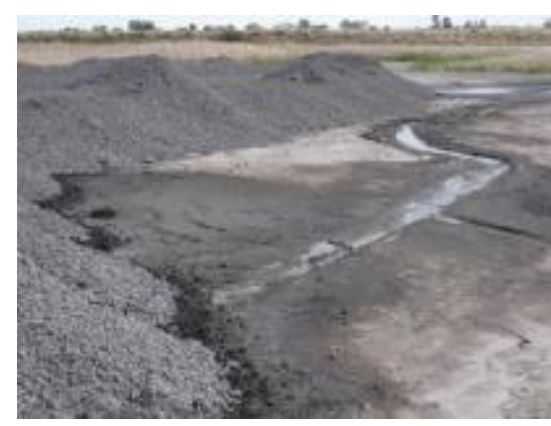

(a)

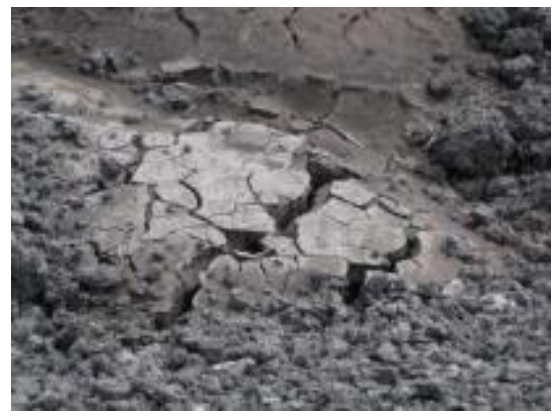

(b)

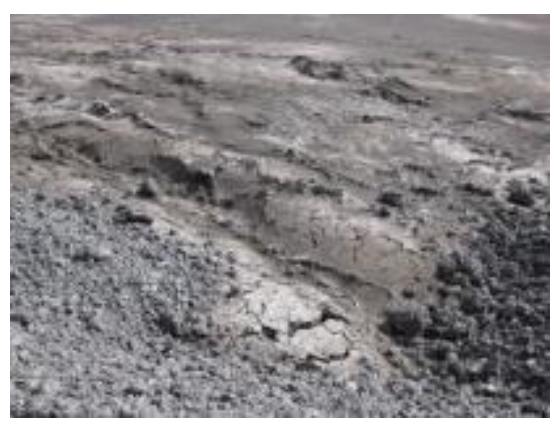

(c)

Figure 14 Fill placement causing: (a) water table rise to tailings surface, (b) hydraulic fractures radiating out from toe of fill, and (c) formation of a bow-wave on continued dozing

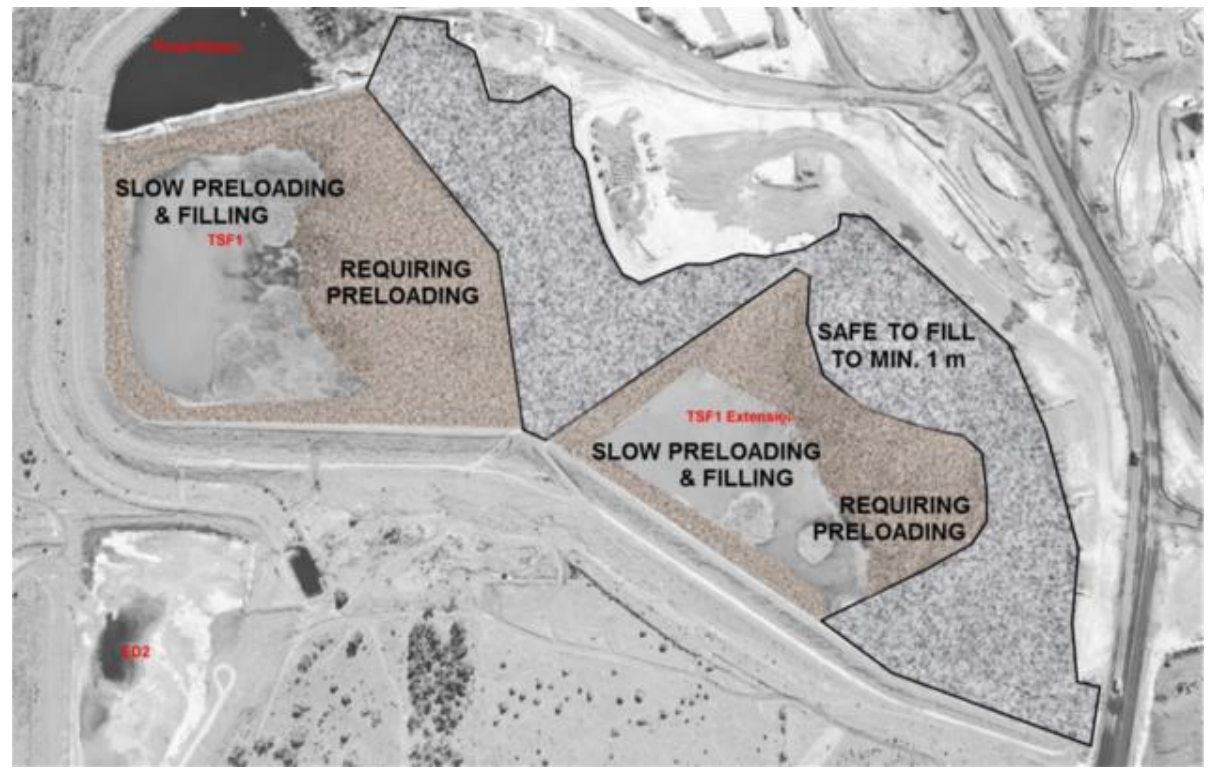

Figure 15 Schematic of identified zones over surface TSF

Three zones were identified over the area of the New Acland surface TSF (Figure 15), with the following recommended capping procedures:

1. Old bow-wave areas (along northern side of TSF1 and eastern side of TSF1 Extension):

- Safe to place an initial capping to a minimum $1 \mathrm{~m}$ high:

- $2+m$ at the crest of the old bow-wave.

- $1+m$ between the old bow-waves and to the start of the reeds.

2. Desiccated areas beyond the bow-waves:

- Place 1 to $2 \mathrm{~m}$ of fill preload along the edge.

- Leave for one to four weeks (the timing to be confirmed by further testing), to enable the underlying tailings time to drain and strengthen.

- Gradually push out the preload along a broad front using a D6 Swamp Dozer, to allow progressive drainage and strength gain in the tailings. 
3. Poorly-desiccated and ponded areas:

- Remove water to enable further desiccation.

- Slowly preload the edge, limiting the fill height to avoid bow-wave initiation, which would more than halve the shear strength and safe fill height.

- Leave for one to four weeks, the timing to be confirmed by further testing, to enable the underlying tailings time to drain and strengthen.

- Gradually push out the preload along a broad front using a D6 Swamp Dozer, to allow drainage and strength gain in the tailings, limiting the fill height and rate of filling to avoid bow-wave initiation.

\section{Progress of capping to mid-2015}

The progress of the capping of the New Acland surface TSF to mid-2015 is depicted in Figures 16 to 21 . By mid-2015, the initial capping was nearing completion and the secondary capping layer was following closely behind, being placed by D9 Dozer to save cost and time. It was proposed to complete the initial capping by progressively moving in from the south and the north along the outer western wall of the surface TSF to confine any bow-waving of the soft tailings present. Surcharging the leading edge and allowing time for drainage and strength gain in the tailings will limit bow-waving and scarp formation, and facilitate the safe and effective closure of the initial capping.

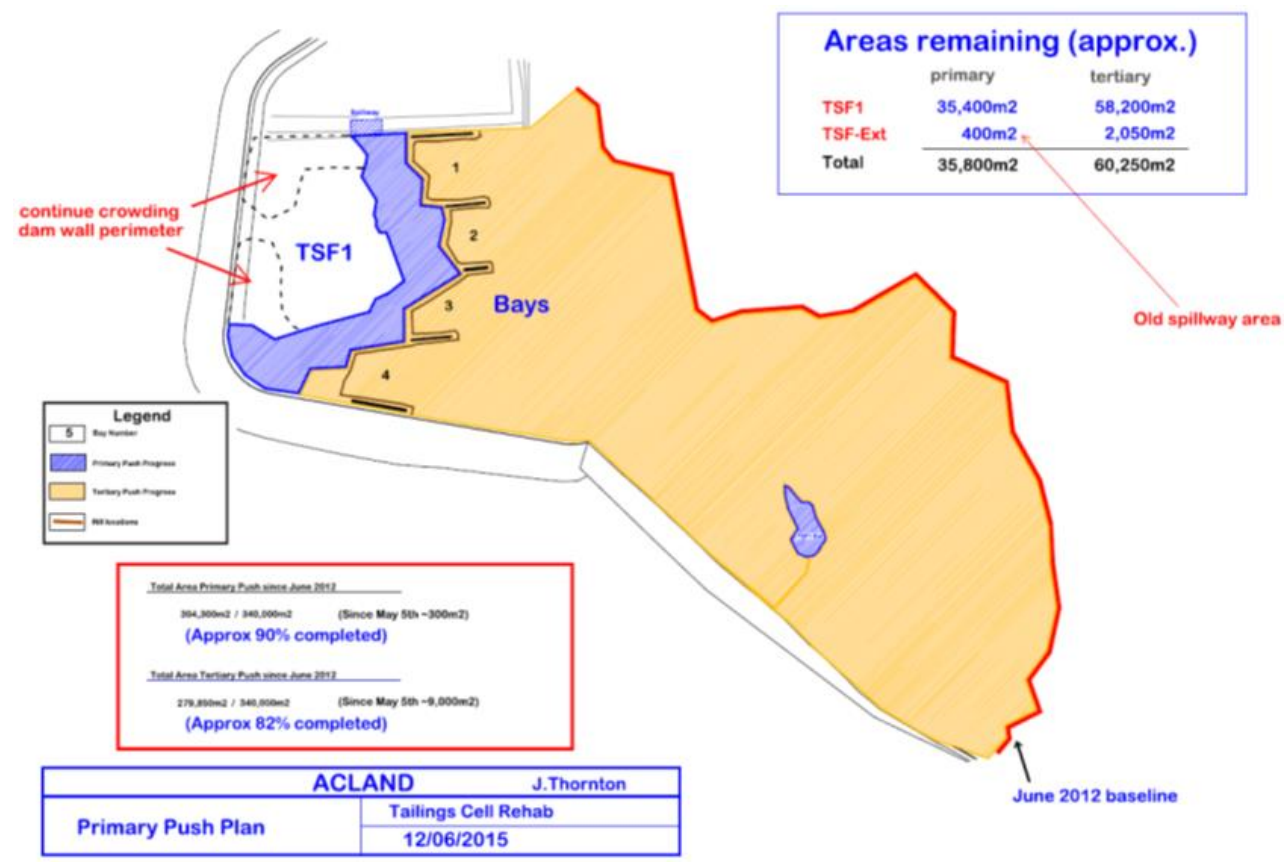

Figure 16 Progress of capping of surface TSF as at 12 June 2015

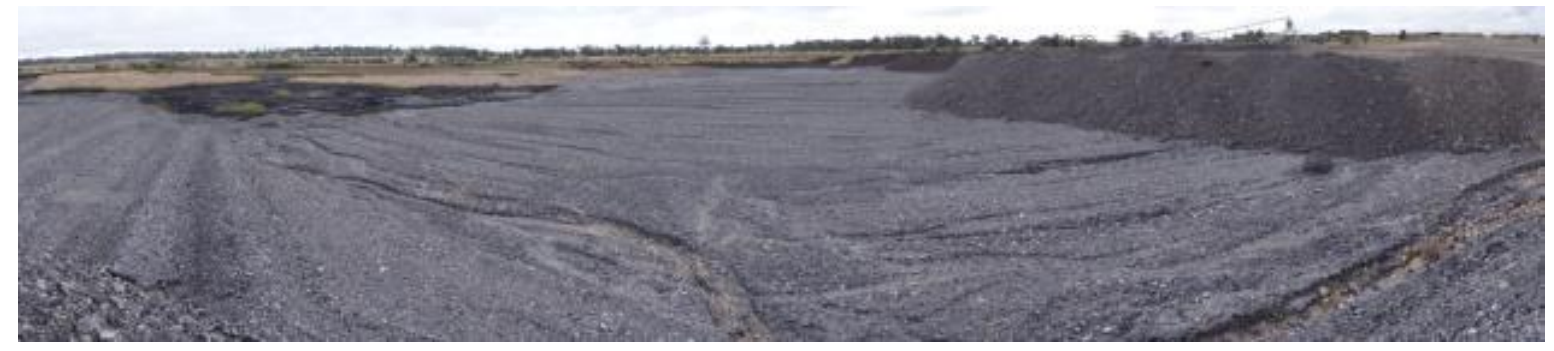

Figure 17 Progress of capping of surface TSF as at 25 June 2015, with all but the northwestern corner of TSF1 capped 


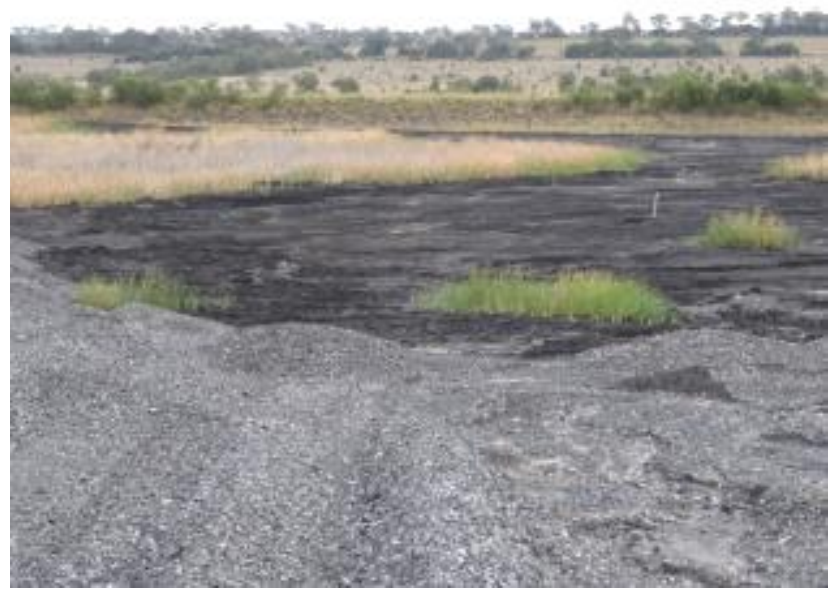

(a)

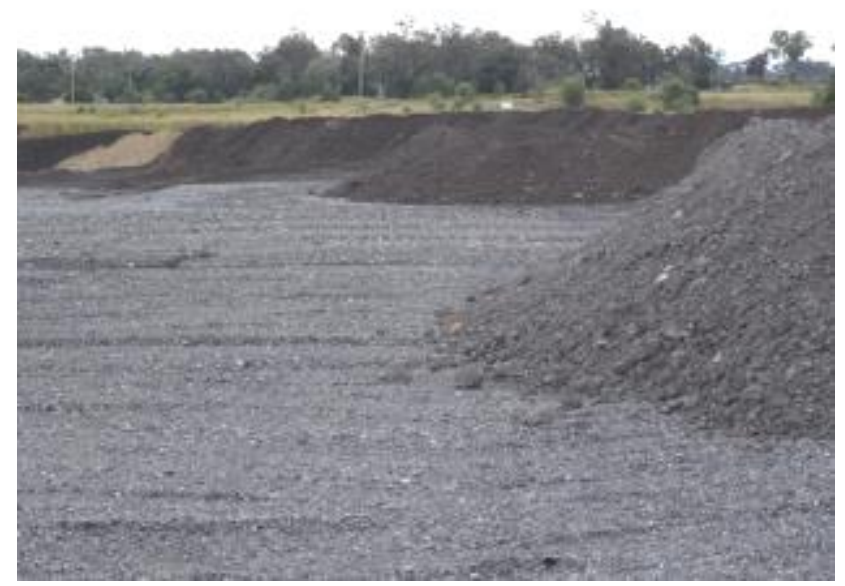

(b)

Figure 18 Detail of: (a) leading edge, and (b) toe of secondary capping
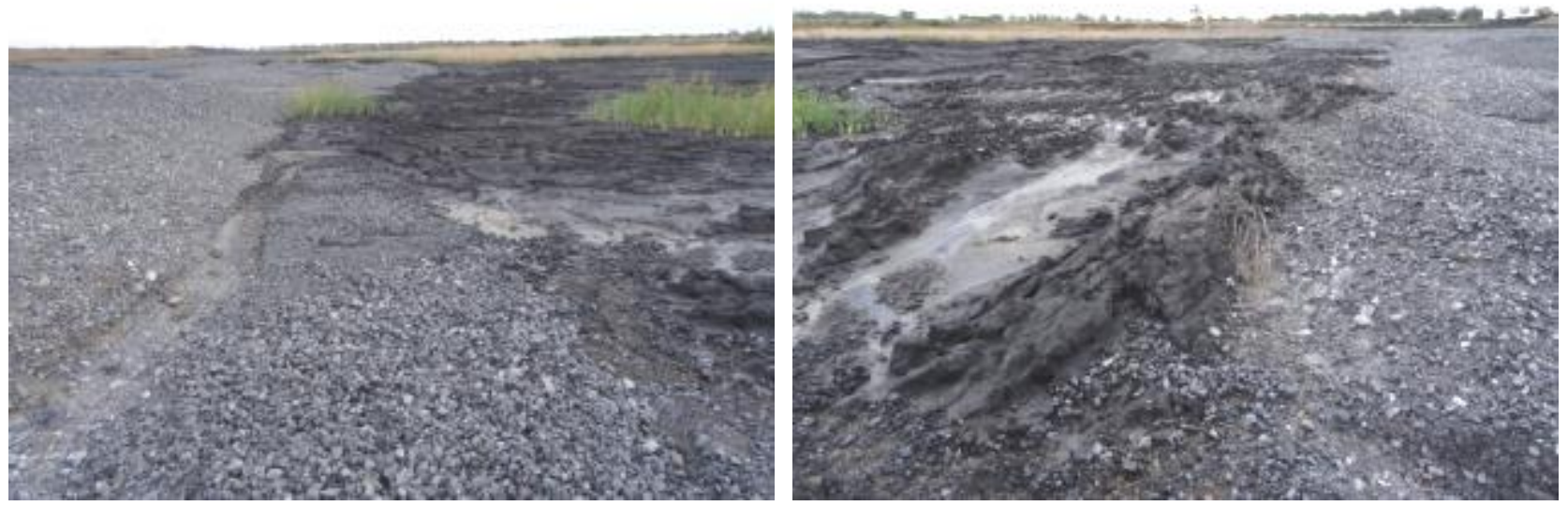

Figure 19 Minor bow-waving of leading edge
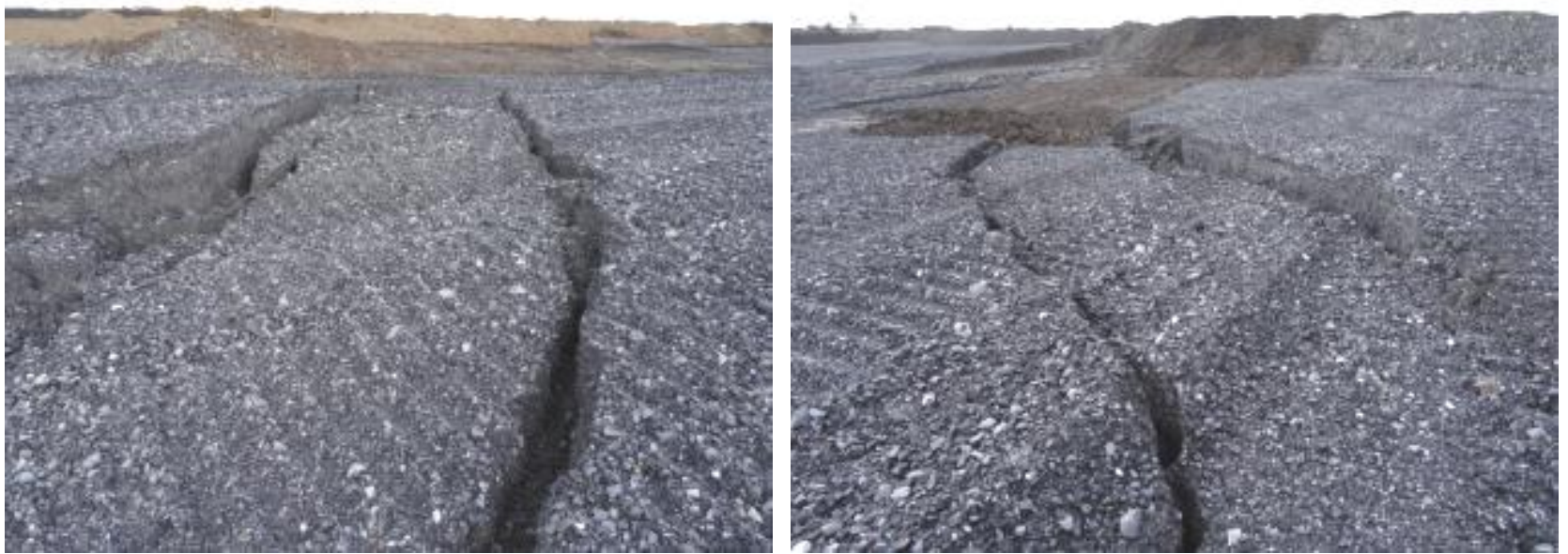

Figure $20 \mathrm{Up}$ to $0.5 \mathrm{~m}$ high scarps in capping over soft tailings 


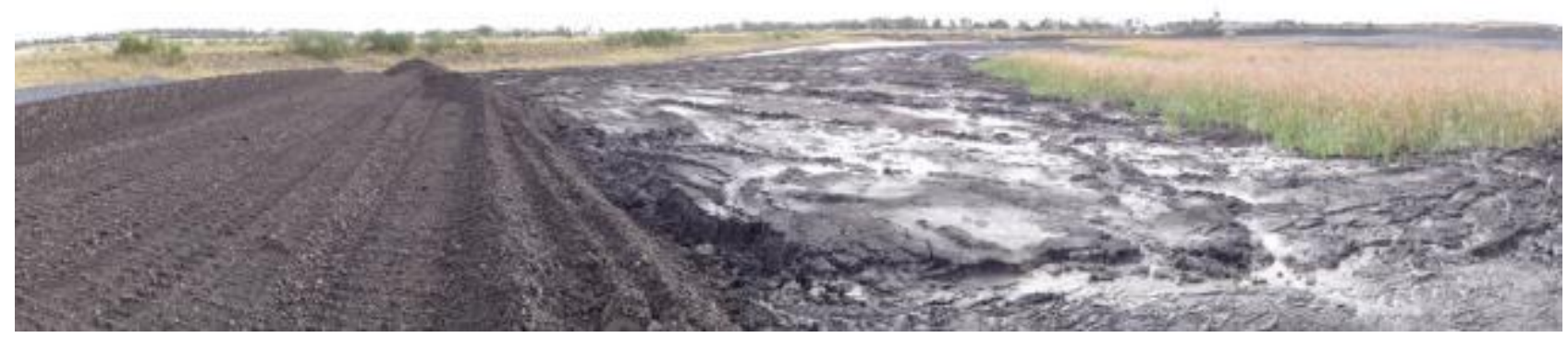

Figure 21 Significant bow-waving beyond latest dozer push onto soft tailings

The secondary capping layer will be completed using a D9 Dozer to save cost and time. Localised tension cracks that appear in places in the secondary capping layer are confined and of little consequence. The completed cap will later be topsoiled and seeded with pasture grasses.

\section{Conclusion}

The paper describes a case study of the successful capping of a completed, conventional, surface slurried coal tailings storage facility at New Acland Mine in Southeast Queensland, Australia. The capping was required to facilitate rehabilitation of the crusted tailings surface for grazing purposes. The strategy adopted was to first identify possible capping methodologies and materials, and to select the preferred method and material. The overall cover selected comprised an initial 1 to $2 \mathrm{~m}$ thick capping layer of coarse reject placed by D6 Swamp Dozer, followed by a second thicker layer of coarse reject, and finally a topsoil layer that was to be seeded and fertilised.

The shear strength and bearing capacity of the crusted coal tailings were first assessed using vane shear strength testing, backed-up by observations of the initial capping of the surface TSF. Capping commenced from the strongest, highest elevation of the tailings beach, and extended towards the ponds. As the capping progressed, further vane shear testing was carried out to assess the shear strength of the tailings beyond the capping layer, and the strength gain over time in the already covered tailings, which enabled further capping material to be safely placed.

\section{Acknowledgement}

The management of New Hope Group's New Acland Coal Mine is acknowledged for providing access and granting approval to publish the tailings capping case study and data described in this paper.

\section{References}

New Hope Group 2015, New Acland, New Hope Group, Queensland, viewed 24 August 2015, http://www.newhopegroup.com.au/ content/projects/operations/new-acland-1

Williams, DJ 2005, 'Placing covers on soft tailings', in B Indraratna \& C Jian (eds), Ground improvement: case histories, Elsevier, Oxford. 
